\title{
SUBCUTANEOUS EMPHYSEMA DUE TO COMPRESSED AIR
}

\author{
BY
}

\author{
G. P. B. WHITTWELL \\ Birmingham
}

Compressed-air tools are of interest by reason of their vibratory action which affects the peripheral circulation of the fingers. Raynaud's syndrome in riveters, pneumatic chisellers and drillers is well known. The harmful effect is almost certainly due to vibration, although cooling of the hands may occur with some pneumatic tools and may be a contributory factor.*

Apart from using compressed air for riveting, burring and drilling operations, there are, however, two other widespread and simpler uses of compressed air in industry, associated with a totally different hazard. It is used as a coolant, i.e. to cool the tool on a lathe or other machine; and, more commonly, to blow away metal chips during machining so that the operator can see the work. A flexible rubber tube with a nozzle is used, rather like a small hosepipe, which most workers sling near their machine. The air pressure is about $70 \mathrm{lb}$. per square inch, which is capable of dimpling the back of the clenched fist quite deeply even when the nozzle is held several inches away. Considering its widespread use it is surprising that accidents are not more frequent ; they are common enough, however, and are known to experienced industrial nurses. Several cases have come to my notice where there was skin trauma through which air entry caused subcutaneous emphysema.

A typical history is that of a healthy young man working in an aero-engine works. While milling a steel component a piece of metal pierced the pulp of the middle left finger. He removed the 'swarf' and continued to work, holding the components in his left hand while he used the compressed air on them. In a few minutes the injured finger had gone quite white. The terminal part of the finger was like "washerwoman's finger'-white, insensitive, and slightly tense. An hour and forty minutes later he had the typical 'crackling' swelling of emphysema over the dorsum of the hand and on the radial side of the extensor surface of the forearm as far as the elbow. There was no further extension of the swelling, but the finger was

* Against this is the fact that the writer has seen Raynaud's syndrome in flexible shaft polishers using a large polishing wheel at excessive speed. The wheel, which resembles a large-sized dentist's drill, caused ' white fingers' in 9-12 months in a few men who, being
on piecework and inexperienced, used the electric motor at top speed. on piecework and inexperienced, used the electric motor at top speed.
This instrument works warm, so that the harmful effect must be purely vibratory. then red and aching. He was sent home and the condition disappeared within twenty-four hours. Kept . under observation for a few days no sepsis developed, and there were no untoward results. He lost only one shift from work.

The literature reveals only one reported case of emphysema due to a similar cause. This was recorded by Blau (1928) as a peculiar and so far undescribed injury. Skin trauma was present-a cut in the right forefinger-and compressed air was accidentally allowed to play on the wound. There were no after-effects and the emphysema disappeared within a few days. Blau found it difficult to believe that compressed air, which would have little pressure after leaving the tube, could cause the accident, but after personally handling one of these air blast tubes I have little doubt that air could enter even through a small puncture-as in the case reported above.

Pneumatic rupture of the rectum due to compressed air tools has been reported by Finnegan (1923), and subcutaneous emphysema of the hand by Parker (1937) - due to a man accidentally putting his hand over the exhaust of a pneumatic driller. In this latter case a cut was present and the emphysema disappeared in a day.

The condition is obviously allied to 'grease-gun finger' where oil is forced under very high pressure into the fingers, possibly through a lesion of the skin, and where sometimes gangrene may supervene.

\section{Summary}

Apart from its use with pneumatic tools compressed air is commonly used in the engineering industry, (a) as a coolant, and (b) to blow away metal particles from the cutting area of machine tools.

If the operator has already sustained skin trauma there is a risk of air entering the wound and causing subcutaneous emphysema. A typical case is recorded.

\section{REFERENCES}

Blau, R. (1928). Z Zbl. Gewerbehyg., 5, 97.

Finnegan, P. J. (1923). Boston med. surg. J., 188, 15. Parker, W. S. (1937). J. roy. nav. med. serv., 23, 347. 